the preceding reasoning with the reality, it has been necessary to examine a normal visual field, once with a small white central fixation point, and then with a fixation ring. The result of this examination with a small coloured ball made on the abovementioned screen is that there is no more difference between the two tests than between two successive tests with a central fixation point.

For normal observers, however, fixation of the centre of a ring is - more difficult than fixation in the ordinary manner, so that the first method should only be used with patients having central scotomata, hemianopsia, etc., as one can also hold the gaze fairly well through part of a ring - the rings can easily be made visible on the above screen. This is done as follows: Small aluminium plates, which have been made slightly globular, are attached to the centre of the screen by means of a small bolt on the back, and a nut. A white ring of a few millimetres breadth is painted in the periphery of these plates, which must be of different diameter, so that they can be seen at different angles, whilst, again, the centre of the plate is either painted black or covered with black material. Owing to the slightly globular inclination to the front, the balls run easily on the discs, the centre of which can be tested also in this manner.

\title{
DISCUSSION ON PERIMETRIC METHODS
}

Professor Van der Hoeve (Leyden), wished to congratulate Dr. Peter on the very accurate and scientific way in which he had treated the subject.

It was the duty of the ophthalmic practitioner to carry out his perimetric methods as rapidly as was consistent with accuracy, for it must always be borne in mind that hurry and exact perimetric examination do not agree. Perhaps it would be better to make no perimetric examination at all than to do it hurriedly; haste might cause the observer to overlook many valuable scotomata. Exact perimetric examination must occupy a deal of time, more time than can properly be spared in the hurly-burly of a polyclinic; it asks two things: time and patience on both sides, i.e., on that of the patient and on that of the doctor. Therefore we have to make our methods as good as possible for quick examination and take advantage of as much assistance as will enable us to carry it out at our ease.

A second point which ${ }^{\prime}$ must be considered is the size of the object. We should not continue to diminish the size of the object and increase the distance of the patient from the screen as otherwise we shall be more and more troubled with physiological scotomata. 
The warning of von Hess that in some of our modern methods of perimetry, the image of the object on the retina has a much smaller diameter than the vessels must be borne in mind.

Neither the radial, nor the concentric moving of the object, nor yet the moving perpendicular to the nerve fibres is the only rational method. If there is one rational method of moving the object to the exclusion of all others, it is that of moving the object perpendicularly to the boundaries of the area we wish to map out, that is to say to the periphery and boundaries of the scotomata.

To be able to carry this out we must first find out where the scotoma area is and then change the direction according to the circumstances.

To find out every scotoma, without omission of a single one, it is absolutely necessary to touch each part of the visual field with our object and it is exactly the same whichever way we do this, either by horizontal, oblique, radial, or concentric moving or by moving perpendicularly to the nerve fibres, or even by moving quite irregularly if only we ramble all over the visual field and touch every point of it. This is an immense task, but happily for us, most of the scotomata, at least the most important, may be found in the central part of the visual field, so we may examine this as carefully as possible and do the much larger periphery rather more rapidly. In doing so we must, however, not confine ourselves to the papillo-macular field only, but exceed this region in every direction.

Perhaps the following is the best method: After carefully mapping out the blind spot we encircle this in two or three circles, the first very close to the blind spot, the others at some distance and we then ramble with vertical movements all over a region from about $15^{\circ}$ on either side of the fixation point and the same distance vertically,

In this way we are sure to find out every central and paracentral scotoma for we cross continually the place where Bjerrum's arcuate scotoma may be found and, moreover, we touch several times the projection of the raphe retinae.

The raphe retinae is a very important region because it is here that Bjerrum's scotoma may begin. He agreed fully with Lt.-Col. Elliot that Seidel's sign (the wing-shaped enlargement of the blind spot) is a very important one for the early diagnosis of glaucoma, but Bjerrum's scotoma may begin at other spots too, for he had seen many patients where the scotoma first appeared at the raphe retinae, indeed, in some cases Bjerrum's arcuate scotoma was complete except for the spot touching the blind spot so that we had a negative Seidel's sign.

Bjerrum's scotoma never, or hardly ever begins in its whole extent 
all at once, it may begin at every point of the bow and extend from there. It may even start at another point and the two scotomata join together. The scotoma may be absolute or relative, or have absolute and relative parts.

Lastly, he wished to utter a warning against the law laid down by Igersheimer, that in every scotoma caused by disease of the optic nerve, and also by glaucoma, a brìdge is present between the scotoma and the blind spot.

Every ophthalmologist knows how often in retro-bulbar neuritis the central scotoma, without bridge to the blind spot, is the principal sign.

Dr. A. H. H. Sinclair (Edinburgh) said it gave him great pleasure to congratulate Dr. Peter upon his paper, which was a most comprehensive statement on the modern aspects of the subject. It expressed fully and adequately, and in a most interesting way many of the things he had thought of in regard to the use of the screen test and the perimeter. Hè was disposed to say the perimeter should not be ruthlessly put on one side: it was an instrument which, as a rule, was very badly made. He thought perimeters should be made free from mechanical devices for moving the test object : this should be moved by hand, and the instrument should be limited in employment to the cases for which it was suited, to map out absolute scotomata and the limits of the visual field. It should be placed in front of a black screen when used. When the test was for white, the use of a small test object was important, because if one larger than was necessary to stimulate vision at the periphery of the field was used, defects might readily be missed. For colour testings the object should be larger, as Dr. Peter had said. He would not enlarge upon that.

With regard to the campimeter and screen, he had no practical experience of Dr. Peter's instrument, but had used the Bjerrum screen for twenty years. In his consulting room he used a 1-metre screen, while for more delicate work he preferred a 2-metre screen. He thought that his practice in this matter would be supported by others who had dealt with the more difficult work in connection with tracing scotomata of relative type. Dr. Walker, in Boston, U.S.A., had used a large screen with a very small test-object. Dr. Traquair had carried out his work with the large screen. The speaker had watched Dr. Traquair's work in Edinburgh and valued it very highly. The screen or campimeter was of value for the central zones of the field, but not for the periphery. Within a zone of $30^{\circ}$ it was incomparably more valuable than the perimeter, especially for the detection of early relative defects, and workers who wished to have a real knowledge of the functional state of the central portion of the field should use a campimeter or screen. The 
Peter's campimeter he had not used, but he hoped to become familiar with it in practice, for, as far as he could judge, it appeared to be a useful instrument.

The Bjerrum screen was intended to be used with a small white test-object; the colour tests made by it were not so satisfactory, but were also of great value. For white, the size of the test-object could, if properly used, be very much reduced without leading to errors in observation. The test-object should be moved from the blind area to the seeing area, and also in the reverse direction. It should be moved in a concentric or circular way as well as radially. In fact, the freedom of movement which is gained by holding the test-object on a fine dull black rod, and moving it by hand, is a factor of primary importance in securing the closest approximation possible in the correct mapping out of a relative scotoma.

The value of the perimeter and screen test, and of all tests applied to the field of vision in addition to their value to the ophthalmic surgeon in glaucoma and other diseases of the eye, lay largely in the relationship of the findings to general medicine. This aspect of the matter was not yet sufficiently realized. Physicians and surgeons did take patients' fields with the perimeter, but did not know or sufficiently value what could be done with the aid of the finer methods. The screen test in certain cases gave information of the utmost value. It would be well if ophthalmic surgeons could impress upon students and doctors, especially on those interested in neurology, the value of the more refined methods of field examination. He regretted that when recently in Boston, he did not see Dr. Walker, but was much interested there to see something of the work which had been done, and was going on, and some of the apparatus in use. $\mathrm{He}$ had had the privilege of meeting Professor Cushing, and was greatly interested to see what importance that authority on brain surgery placed on the results of an expert examination of the field of vision in his patients. The great value of the screen test and perimeter in diagnosis is still becoming more and more evident. It was of the utmost importance to get at the very earliest signs in diseased conditions, and it was in the matter of early diagnosis that the value of the tests, now under consideration, should be emphasised. . It had been of very great interest to him to hear Dr. Peter's paper.

Professor Harvey Cushing (Boston, U.S.A.) said, in reply to the Master's invitation to him to speak, that he felt somewhat humiliated to be found here taking notes, but there remained nothing for him but to confess his guilt in that matter.

$\mathrm{He}$ attended there on that occasion to see what an Ophthalmological Society looked like, expecting to stay only a moment, as he 
had other duties elsewhere; yet he found himself so greatly interested that he had remained all the morning. He was, perhaps, more interested in a discussion on the "humanities" which was proceeding when he arrived, something which, he was sure, would not take place in an American Ophthalmological Society, because there they did not know the difference between Latin and Greek! And he had listened with tremendous interest to the author's report of his group of cases, which to most, he thought, meant a new syndrome, and it constituted a very important contribution to medicine. He had seen some of these cases, and freely confessed that he did not know what they were. He would now go home, and spend his declining days going through the asylums over there - he hoped merely as an observer of patients ; and, as someone had hinted, he might even find some examples in the United States Senate of mental disturbance in some degree.

The whole question of perimetry was of more interest to those who did not pretend to be ophthalmologists than might be imagined. The whole story of instruments of precision was a story which went from the early days of medicine. All were striving to produce instruments of precision. It was not so very long ago that a similar discussion was taking place among a body of physicians regarding different kinds of thermometers, or, possibly, different kinds of watches, for Fleury was endeavouring to count the pulse by simply the swing of the pendulum, so that he came to speak of a pulse as a "10-inch" or a "12-inch" pulse; he got a pendulum to swing synchronously with the pulse. The introduction of these instruments meant the taking of more and more time for the working of a clinic; the calorimeter might take a morning for the taking of an observation, and similarly with the electro-cardiograph. The perimeter was an old instrument, and in many clinics, he grieved to say, it was used very little, but he supposed that to everyone who was devoted to patients with intracranial disorders, very largely cases of tumour, the perimeter became a most important adjunct, not only as a means of diagnosis, but also for determining the advance or the subsidence of the disease. That was particularly the case now that the surgeon had invaded the field of pituitary tumours. Studies such as had been put before this meeting therefore became of vital importance to those engaged in this work.

What were they to do? Must they have an expert ophthalmologist, who had had a special training in perimetry, to carry. out these procedures? Or must the taking of these observations be simplified in such a way that a junior in the clinic could make sufficiently reliable observations. Perimetry was difficult, it required much interpretation, and the patient's interpretation required interpreting. Also the patient became fatigued, and hence 
much judgment on the part of the observer was called for. Having made many such observations he knew how difficult they were. $\mathrm{He}$ also knew how they were misled into writing a very unfortunate paper many years ago, in which they tried to talk about the interlacing of colour fields. And though he felt sorry they put that paper out as a means of diagnosing brain tumours before choked disc appeared, and before there was swelling of the papilla, nevertheless it did good, because it led to many practitioners using the perimeter; hence, by the mistake of the authors of that paper, the instrument was again used in many clinics where it had fallen into disuse. To-day, certainly it must be regarded as an absolute necessity. And it could not remain an instrument to be used solely by ophthalmologists, any more than it could be said that no one except eertain specialists must use the stethoscope. Hence it was obligatory on ophthalmic surgeons to find some standard on which all could agree as an instrument good enough for all, though it would not necessarily be "fool-proof," for no instrument in regard to which interpretations were necessary could be fool-proof. The matters which this meeting had been discussing and which interested experts in this line very greatly, such as the detection of scotomata, the enlargement of the blind spot, and cases of glaucoma and retro-bulbar neuritis-whatever that term might mean-he did not pretend to know very much about. But when it came to a matter of changes in the periphery of the field, brain surgeons and others did know something about that, it was what they were chiefly interested in. It was a good many years ago that they began to take, in a routine way, the fields of every patient who came in and was even suspected to have a brain tumour, every case in which there were pressure manifestations. Some of the men on whom this work devolved became very expert at it. Walker, for instance, was a mathematical genius of the Helmholtzian order: he took to this work, and, using largely the Bjerrum screen, detected very early pressure changes, especially changes in the chiasma due to pituitary lesions. Those observations helped him, the speaker, and others enormously in their work. Peripheral changes in the fields should be known, not. only for cases of pituitary disorders, but for asylum cases. He would mention, as an instance, the temporal lobe. His hearers knew how far forward the visual pathway went in the temporal lobe, namely, to the anterior chiasma, and curved round the anterior horn of the ventricles, so that any lesion in the temporal lobe would produce a homonymous defect in the field. Curiously; for a reason he did not know, that defect in the field always came first on the same side as the lesion, and it might advance to a quadrangular defect before any defect came into the opposite field at all. There might be a very minute lesion, a stab wound, perhaps, in the temporal 
lobe, and that would cause a homonymous defect, which passed in almost to the macular region, and that would not be detected unless one examined every $15^{\circ}$ of periphery. Possibly one might find a defect passing in the field of each eye to the macula, and close study was required. In the case of temporal lobe tumours, one could tell by bilateral changes in the field whether the tumour was high or low, because these paths showed the same kind of course through the brain: the geniculo-calcarine pathway as in the geniculate region. Therefore it was necessary that there should be some form of field-taking which was applicable to all patients, one which could be used whether the patient was sitting or was in bed, and which was capable of being employed by those who had not the great skill which was the possession of the ophthalmologist, and which some men might attain to in general clinics. What he hoped was that this meeting, as a result of this discussion, might agree upon something which could be passed on to those interested in ophthalmology, but who in the matter of practice stood only on the threshold of the speciality.

Dr. S. Holth (Christiania) said: I have found the Bjerrum tangent plane method most useful for testing defects in the central visual field. When I began to test this method more than 25 years ago my results, however, were disturbed by the "staring blindness," first observed on unmoved peripheral objects by Troxler, 1802; the cause of this was that I moved the small white objects too slowly, then they disappeared in spots where there did not exist any scotoma. On the other hand, when the observer moves the object too fast he may pass over a real scotoma; he is between Scylla and Charybdis.*

For the testing of the outer limits the perimeter is indispensable. The ordinary arc models (also in the form of the " hand perimeter" of Schweigger) are too cumbersome on travels and at the sick-bed; they are too costly for the general practitioner. For these purposes I have, many years ago, constructed an instrument which has not been demonstrated outside Norway before to-day; it was destined for demonstration at the XIIth Ophthalmological Congress at St. Petersburg, 1914, under the name of "The chord perimeter," and was described in the Transactions of the Congress, Vol. I., p. 123-129; an account of it was printed in the Ophthalmoscope, 1915, p. 14.

My first communication did not point out exactly enough the three different and very useful applications of the instrument:

* S. Holth, “Det. normale synsorgans stirreblonhed," Christiania, 1896. 
(a) as an ordinary perimeter, (b) as a very sensitive test for central scotoma, and (c) as centimetre-dioptre measure in refracting work.

I find it, therefore, necessary to give a new description accompanied by one of the old illustrations and two new ones.

(a) Perimeter.-The principle is as follows: The graduation of the two perimetric circle quadrants are projected on the corresponding chords (Fig. 1).

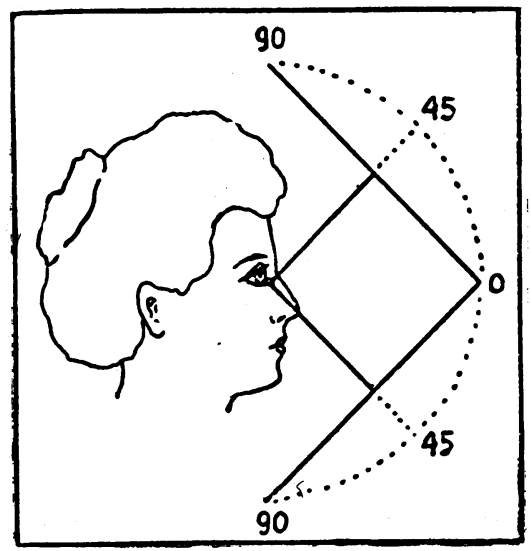

Fig. 1.

Two rules, 27.5 centimetre long, are connected at a right angle by a joint, corresponding to the fixation point of a perimeter; the chord graduation occupies 25 centimetres (Fig. 2). Two metal sticks attached to the rules when at right angles have their connecting point in the centre of the half circle (Fig. 1).

The object holder (see Fig. 2) kept in a deep furrow in one of the rules, is a thin blackened steel stick provided with a white bead of two millimetres diameter on one end and on the other end a cube of vulcanised black rubber, on which four sides have a celluloid disc (white, blue, red, and green) of 7.5 millimetre diameter inlaid.

I have on purpose not provided the chord perimeter with any graduated disc for the meridian positions. The horizontal and the vertical meridian you take exactly by eye measure; for the oblique meridians the error limit is under 2 degrees, which is of no account in clinical perimetry. In many cases it is sufficient according to 
Haab to test the vertical, the horizontal and the meridians $45^{\circ}$

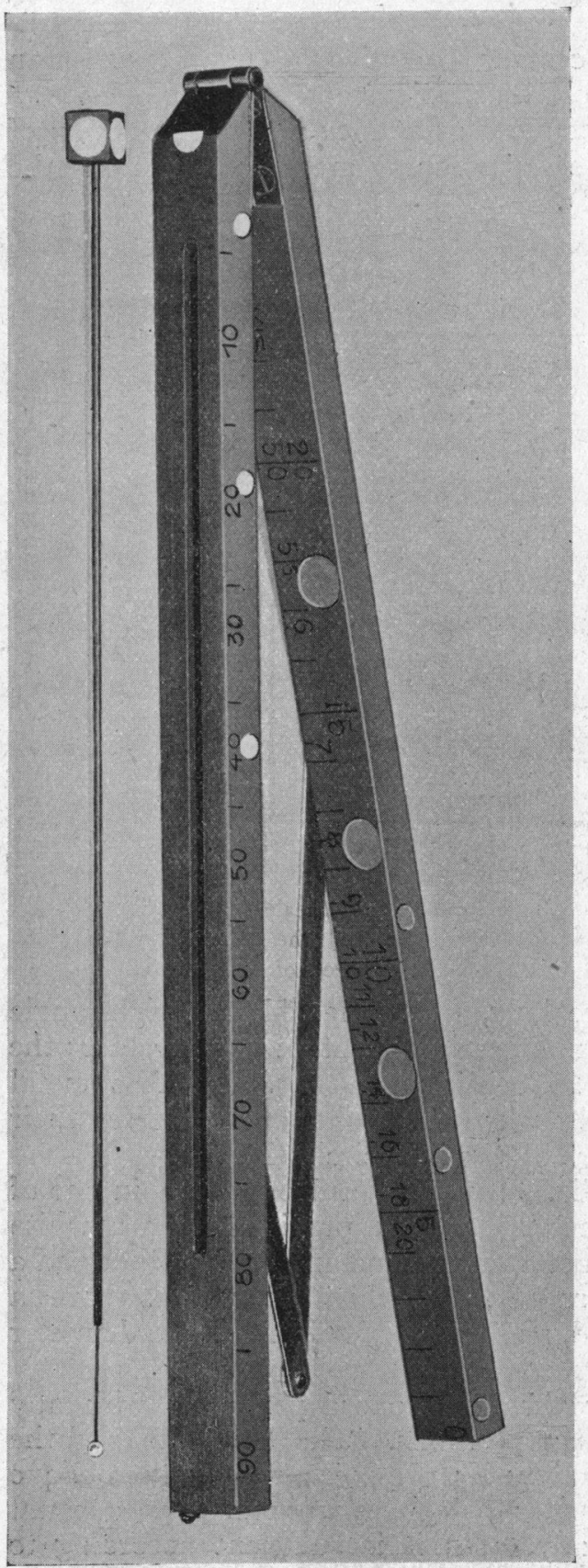
between them $=$ in $^{-}$all 8 directions. It is, however, as easy to test in all the meridians corresponding to the ciphers of the clock dial $=12$ directions; equally in the nasal meridians just above and below the horizontal meridian - important in glaucoma.

The outer limits for colours are always taken by the celluloid discs, often also the limits for white ; but the white limits may also be tested with the white bead which always is seen in the whole normal visual field. Mariotte's spot and other absolute scotomas are also tested with the white bead. I have tested in retinitis pigmentosa beginning a paracentral ring scotoma of $3-10^{\circ}$ extent as exactly in this manner as on a large arc perimeter.

(b) Central scotoma test.-In order to detect central scotoma in intoxication amblyopia and retro-bulbar neuritis I have placed on the outer sides of the rules groups of three identical celluloid discs (Figs. 2 and 3) in pink,

Fig. 2.

The chord perimeter nearly folded together after use ; and the object holder. Reduced in size from 27.5 to 15.5 centimetre. (On the rule to the right the numbers of the perimetrical graduations by a mistake are not reproduced.) 
red, and white (also in green and blue, which, however, are superfluous). When the patient's eye fixes the middle of the three red or pink discs in horizontal position, the colour in the nasal disc is seen distinctly, in the central disc less distinctly, and in the temporal disc obscured, changed or not at all; when the three discs are in vertical position and the middle one fixed, the colour in this is less distinct than in the two others. This comparing three-spottest was formerly placed in a separate instrument (Annales d'Oculistique, 1908, Vol. CXL, p. 169: 175). This method should not be considered as a mere "rough and ready test"; it is true that the test is ready; it is not, however, a rough one-it is really a very delicate and sensitive test. By means of my three-spottest in pink I have detected many cases of beginning tabacco or alcohol amblyopia, while the vision was still between $5 / 6$ and 5/10. I want also to remind you that the same test has enabled me to detect central scotoma in protracted uveitis and in beginning sympathetic ophthalmia (loc. cit. and Bulletins et Mémoirés de la Société française d'Ophtalmologie," Vol. XXVI, 1909, p. 308-309).

(c) Centimetre and dioptre measure.-The two rules of the chord perimeter can be straightened in the central joint and by means of the metal sticks be fixed and converted into a single rule of 55 centimetres, which has also a dioptre graduation from $2.0 \mathrm{D}$ to $20.0 \mathrm{D}$. Fig. 3.

The two first models of the chord perimeter of 1909 (black rubber or aluminium), which I now show you, cannot be straightened; they have no dioptre graduations and they were too expensive.

The actual wooden model can be used in the oculist's office as a very recommendable central scotoma test and as a dioptre rule in refracting work. By the sick bed and on travels it is more convenient for perimetry than ordinary perimeters. The general practitioner needs no other perimeter.

The instrument will be made by John Weiss and Son, Ltd., 287, Oxford Street, London, W.

FIG. 3.

The two rules of the chord perimeter are straightened out and fixed at the joint forming a single rule divided into centimetres and dioptres (from 2.0 D to 20.0 D). Reduced in size from 55 centimetres to 15.8 centimetres). 
Mr. E. H. E. Stack (Bristol) said that practically all the points he had intended to bring forward when he intimated he would speak had already been dealt with by speakers. He therefore would be content with emphasising one point, namely, the importance and value of having a moving disc instead of a fixed one for ordinary perimetry, also the necessity of working from the blind into the seeing area, as well as in the reverse direction.

Another little practical point, which he had found useful in out-patient clinics, was what he called the four or five-point perimetry. What he meant was that the sister, or whoever was helping him in the clinic, was instructed in many of the cases to take a very short perimetry in four directions only-above, below, outside, and inside, or perhaps two on the inside, and in that way he had sometimes found cases which needed a more detailed perimetry. He did not want to emphasise too much this timesaving method, but it enabled cases to be discovered which without that simple routine might be missed.

Lieut.-Colonel R. H. Elliot (London) wished to confine his remarks to glaucoma. Seven years ago, when he was first interested in Seidel's sign, he was unable to find a single instrument maker in London who could supply a Bjerrum's screen. . That was evidence of the small interest then taken in the subject.

Seidel had described a pointed enlargement of the blind spot, which he stated could be found before any other sign of glaucoma was present. It was while studying glaucoma cases for this sign that the speaker evolved his present scotometer. Scotometry is of value in glaucoma in three ways: (1) in the diagnosis of very early cases; (2) in the study of the progress of a case; and (3) in estimating the value of an operation or of a course of treatment. In all these respects his scotometer had proved of the utmost value. He had never claimed for it that it was an instrument for laboratory research, though personally he believed it could easily be made such. But he had brought it forward for the help of the busy practitioner. It combined three principles: (1) Priestley Smith's circular method, as opposed to the radial method; (2) Bjerrum's enlargement of the scotoma ; and (3) the methodical examination of the field at distances of $1^{\circ}$ from the centre out to the $26^{\circ}$ circle. He wished at the same time to insist on the importance of fixation of the head, in such a way that the eye remained throughout the examination at the centre of the system of circles under examination. If this were done, the mechanical attributes of the instrument insured the marking out with mathematical accuracy of the same portion of the field each time a circle was taken; the field could thus be accurately delimited out to the $26^{\circ}$ by 26 rapid and precise observations, whereas, by working along the various meridians, from 
or toward the centre, at degree intervals, 360 observations would be required, and that portion of the chart which lay within $5^{\circ}$ or even $10^{\circ}$ of the centre would be reduced to chaos. Despite all that others may say to the contrary, he regarded Bjerrum's principle of enlargement of the scotomata as of the greatest possible importance. It made work easy and accurate.

Then, with regard to his own contribution to the principles of this scotometer, viz., the methodical examination of the field at degree intervals from the centre out to $26^{\circ}$. It had from the first seemed to him unreasonable that the enlarged blind spot should always end in pointed extremities, as. Seidel said it did. If this enlargement was due to the damage of the optic nerve fibres, as they flowed over the sharp scleral edge of the foramen, it was to be expected that the resulting scotoma would be frayed out into a number of points, owing to the fact that certain nerve bundles would be more damaged than others. Whether this were right or wrong in theory, he had found from the start that in cases; in which there was reason to believe that the nerve fibres were damaged at the disc edge-whether in glaucoma or otherwise- the enlarged blind spot showed a jagged edge, either upwards, or downwards, or both.

It had been suggested that this was an artefact. He would reply that, even if that were partly true, and he did not admit it, it still remained a sign that enabled one to diagnose injury to the nerve fibres at the edge of the disc. This had been proved by the experience of a large number of other surgeons who had confirmed his (the speaker's) findings. If it were asked, why this method should give evidence of this form of damage, when other methods failed to do so, he would reply that the direction of the damaged fibres is a circular one, around the centre of the retina; in using a rotating scotometer, one was following the path of the damaged fibres, and it is in the distribution of the damaged fibres that the jagged appearance of the scotoma finds its explanation; it is much more difficult to delineate a scotoma, when one passes across its narrowest measurement, than when one travels along the path of its greatest dimension.

With regard to the forms assumed by these blind-spot scotomata: one might find a typically enlarged blind spot with the edges jagged throughout its whole breadth, both above and below; again, one might find a single narrow arc-like belt of relative or absolute scotoma, continued along one or two degree circles only; or the blind spot might show little or nothing abnormal, and yet at some distant part of the periphery a commencing relative or absolute scotoma could be mapped out with this scotometer. Still other varieties could be found. He believed that the cause was the same in all, namely injury to nerve fibres at the edge of the disc. Why 
then these marked differences? The answer lay in anatomical peculiarities of two distinct kinds, viz., (1) in the method of distribution of the nerve fibre bundles as they pass out of the papilla, and (2) in ill-understood physical variations of the scleral edge, which determined a patchy yielding of its circumference, and a correspondingly patchy lesion of the neighbouring nerve fibres.

With every deference for the opinion of others, he believed that in early cases the enlargement of the blind spot in glaucoma could be mapped out for all clinical purposes, by the use of small objects (grey if necessary) without resorting to the use of colours at all. Later, when vision was poor, larger objects (discs of white blotting paper) could be used on his scotometer, by the well-known method of Priestley Smith.

In using his scotometer, it was open to the examiner to travel in whatever way his fancy dictated, whether always in one, forward direction, or back and forth, from blind into seeing, or from seeing into blind. He thought they would find that the scotomata would be most exaggerated, if they adopted the second of those methods (from blind into seeing), but the differences would only be small in any case, and would rarely exceed two or three degrees.

He cordially agreed with Priestley Smith, that the ordinary (33 $\mathrm{cm}$. radius) perimeter was of great value in marking out the rough outlines of a field, in glaucoma cases, and that when the concentric method was used it would very often indeed show that valuable and too little elicited sign, Rönne's step.

In closing he paid a warm tribute to Dr. Peter's work in connection with perimetry, which had been of great value to ophthalmic surgery and medicine.

Dr. A. Maitland Ramsay (Glasgow) wished to join with other speakers in thanking Dr. Peter for his excellent paper. That gentleman had treated the subject so exhaustively that he, the speaker, did not feel there was anything useful that he could add to the discussion. Whatever instrument or method employed, he thought it would be agreed that patience and thoroughness on the part of the examiner were necessary in order to get accurate results.

He would like to say a word as to the elongation of the blind spot which was sometimes met with in association with sympathetic irritation. That observation was described in the January number of the Oshthalmic Review, 1906, by Dr. Sutherland and himself. Dr. Sutherland made the observation in a case of pronounced sympathetic irritation, and the value of the observation depended on the fact that after the injured eye had been removed the shape of the blind spot again became normal. Since then, he had himself come to place great value on the examination of the 
blind spot in all cases of sympathetic trouble, and had found Dr. Peter's campimeter of the greatest value in enabling him to do this accurately and quickly. When he found that spindle-shaped enlargement of the blind spot, present in sympathetic irritation, he knew he must enucleate without delay, whereas if it were absent he felt justified in holding his hand.

Major A. E. J. Lister, I.M.S. said he, like the last speaker, had come unprepared to take part in the discussion, but there was one small matter which might interest the meeting, and he placed the responsibility for showing it on Dr. Peter, because he very kindly encouraged the speaker to do so. He wished to thank Dr. Peter very much indeed for his splendid paper.

Many of those practising abroad had not got some of these instruments on hand, and sometimes they were sent for to see special cases. While he was on leave in the Himalayas, he was sent for a long distance to see a most important man in India. 'On arrival, he found the patient had got glaucoma. His services, at that time especially, were so valuable to the Empire, that operation could not be thought of unless it proved to be absolutely imperative. $\mathrm{He}$, the speaker, borrowed a black billiard cloth and put it against the wall, and, with the help of an assistant, he mapped out with chalk his scotoma. He then put in eserin and took another tracing on the black cloth, and put over it tracing paper, and opposite the white marks he put the black marks on the tracing. He saw the patient every six weeks, under the same conditions exactly, taking a tracing and placing it over the others, so that he was able to know exactly what was the course of the scotoma. Dr. Peter and Colonel Elliot would bear him out that this was a valuable indication as to one's duty in a case. The patient was able to avoid operation and continue his work for ten months, and he felt very happy about the case because he knew him to be safe. His advice was that that gentleman should be trephined. His advice was not taken, and he went to somebody else and had iridectomy done. He came back, and then the scotoma was nearly on to the fixation point. He again told the patient he must be trephined, and it was done, by a gentleman in this room, and the sight was saved.

He mentioned the incident because such extemporised methods were useful to men practising abroad, where they had not the advantage of such instruments as those shown and spoken of to-day.

Mr. T. Harrison Butler (Leamington Spa), said that in using the ordinary Bjerrum screen he measured the distances from the centre with Sinclair's tangent scale. In order to measure the angular distances he used a carpenter's rule. The best varieties have 
a scale of degrees at the pivot. By opening the scale to $10,20,30$ degrees, etc., one could apply it to the screen and read off the angular distance of the various scotomata. By this means the reading of the screen could be transferred to Traquair's charts.

Mr. E. Burdon-Cooper (Bath) said the method spoken of to-day had been measurements on the tangent. The blind spot could be measured longitudinally. Remarkably few had adopted the longitudinal method of measuring it. His method of measuring the blind spot, was based on the ordinary physiological test. Of two spots on a card one looked at the central one with one eye in such a way that the other spot fell on the blind spot of the eye. By approximating or receding the chart two points could be found on a longitudinal graduated bar where the spot just disappeared or reappeared. The longitudinal distance between these two points was a measure of the blind spot. He had an instrument by which in 30 seconds an accurate measurement of one diameter of the blind spot could be determined. It was an easy method, and quick, and it afforded valuable information.

Mr.E.E. Maddox (Bournemouth) spoke of the usefulness of a hatpin stuck into the side of a small cork for perimetric observations. $\mathrm{He}$ had been much interested in, and indebted for, what he had heard to-day, and agreed that large objects appeared to. come into the periphery more quickly than did smaller ones. If he watched for a finger coming into his field, he at once saw also his hand, which was further out. For ordinary work, to single out cases for the perimeter, we wanted a rapid method, which would not occupy more than half a minute, and the cork on the white hat-pin which he uses can be so held between the thumb and forefinger, as to give active motion to the head of the pin without any visible motion of the hand, owing to the cylindrical shape of the cork. Thus there was no danger of a complication from any movement of the fingers being seen. $\mathrm{He}$ also emphasized the fact that it was best to have a moving object for ascertaining the condition of the periphery of the field. He supposed that indirect vision could be regarded as'a kind of scout for the macula', and the peripheral retina had, as its function, the consciousness of large objects, bright objects, or moving objects, in order that, if they were important, the macula might be turned towards them, especially moving objects, in the interests of self-preservation. Moreover, by the use of a moving test-object and causing its vibrations to cease now and then, the patient's statements could be tested for veracity. It was well known that astronomers could see a star better by looking at it a little peripherally, as central vision was not the best for a 
bright object. Probably the reason was that the fovea was so precious that Nature had endowed it with amber-coloured spectacles, as it were, instead of having them over the whole eye.

Mr. P. G. Doyne (London) said that in the last few months he had taken a certain number of observations on the blind spot and region in cases of myapia, using Elliot's scotometer chiefly, sometimes.Bjerrum's screen. He had not yet taken enough to base definite conclusions on them, but in some, one got appearances similar to Seidel's sign. Where, in myopia, one saw signs of atrophy or stretching in the immediate neighbourhood of the disc, it did not follow that this was a scotomatous area. Often it did not show up as a scotoma at all. Recently he had a case which had a large inferior crescent, about 1 to 2 papilla diameters across, and the blind spot showed no enlargement at all.

Dr. Peter, in replying on the discussion, said he fully appreciated the very generous attention which had been given to the subject, and there had been so many points touched on that he felt repaid for having come simply by that discussion.

He would refer now only to two or three matters. Dr. Hoeve made use of a most apt expression in referring to the direction in which the test-object should be moved when he spoke of "rambling." That was just the term to think of when mapping out fields. As another speaker had pointed out, they did not always want to think of radial movement, but of every possible movement in developing the field when determining the presence of a defect. The rambling method would bring out the points.

$\mathrm{Mr}$. Sinclair spoke of the relationship of this subject to medicine, and that, too, was an exceedingly important matter. He did not think it was fully grasped that more general practitioners should do perimetry in the rough, and, as Major Lister well pointed out, they did not need for that the elaborate apparatus referred to in this discussion. With ordinary blackboards and Snellen's type much could be done.

Dr. Marx had spoken of avoiding annoying appearances from outside when examining, and he, the speaker, agreed that the surrounding field should be kept free from disconcerting objects. And it was very helpful for the operator to wear a grey gown. $\mathrm{He}$ believed the time was coming when black would be removed from the screens, and some neutral shade, such as grey, substituted. The new perimeter of Ferree was in grey, and the test-object was a peculiar shade of grey, which corresponded to the brightness of the colour which had been used.

He did not read out that part of his paper which dealt with 
fixation and central scotoma: he had been much interested in Dr. Marx's method of determining the fields in the presence of bilateral central scotomata. The method he used was a combination of perimeter and scotometer, one similar to that for measuring squint. The patient was placed in front of a perimeter, and as he could not fix the fixation point, his vision moved out along the line until this point came into view. Then one passed the luminous ophthalmoscope along the àrc of the perimeter until it came to the centre of the pupil, and then it was ofead in degrees. The measurements were then taken on the other side, above and below. That gave four points by which the patient could absolutely fix. The points could, if the observer chose, be connected by a circle. Then one proceeded to map out the scotomata on a tangent plane.

His good friend Colonel Elliot and he were really closer together on this subject than might be thought. During the few days he had had the opportunity of being present at his home, he had 'done his best to get him to explain to him his scotometer. To-day he succeeded better by offering a little friendly criticism, which resulted in Colonel Elliot pointing out the excellent features in his campimeter. He agreed that it was an excellent tangent screen. That point was, perhaps, the best of all, because accurate fixation was essential.

With regard to the criticism concerning the blind spot, he was glad to learn that Colonel Elliot's instrument revolved both ways. In passing from the seeing part of the retina to the blind part, it was desirable to go a little further. If the two points were connected, it would result in a sharp angle. In his criticism he referred more to the lateral part than to the. blind spot. To say that scotomata in glaucoma developed only from the blind spot was not an accurate statement: they would as frequently develop in the sites he indicated on the diagram, and eventually run into the blind spot and become continuous with it. Fuchs said that the nerve fibres on the periphery of the blind spot supplied the part of the retina which was in immediate juxtaposition, and then travelled further and further, until one saw the raphe and sometimes the longer fibres might be affected first. He considered that Colonel Elliot's instrument was one of the best, and that those who possessed it would continue to use it, and that those who had not got it would buy one.

He was glad Major Lister narrated that very practical method of working under difficult conditions. He showed that simple methods could reveal valuable information.

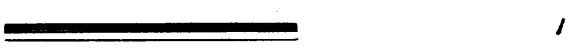

